\title{
Aplicando Conceitos de 5S em um Sistema de Gestão de Estoques numa Indústria Alimentícia e Impactos na Racionalização de Recursos
}

\author{
Paula V. P. Naves
}

A integração de conceitos como $5 \mathrm{~S}$ e gestão não necessita de grandes investimentos para sua implementação, permitindo discutir as vantagens que as organizações alcançam com a adoção do Programa 5S na Gestão dos Estoques. Este artigo apresenta conceitos revisados que podem ser replicados a qualquer segmento industrial e um estudo de caso de um fabricante de alimentos que através do Programa 5S preparou a empresa para implantação das normas ISO, observando impacto positivo na gestão de estoques, sobre as operações de movimentação, armazenagem e de pessoal, gerando otimização de recursos e uma maior motivação aos colaboradores.

\section{Palavras-chave: gestão; alimentos; armazenagem.}

The integration of concepts such as $5 \mathrm{~S}$ management and does not require large investments for its implementation, allowing discuss the benefits organizations achieve by adopting the 5S Program in Stockpile Management. This article presents revised concepts that can be replicated to any industrial sector and a case study of a food manufacturer that through the 5S Program prepared the company for the implementation of ISO standards, noting positive impact on inventory management on handling operations, storage and personnel, generating resource optimization and greater motivation to reviewers.

Keywords: management; foods; storage. 


\section{Introdução}

Segundo Bizelli (2002)1, após a abertura do mercado brasileiro em 1990, diversas empresas tiveram que se adaptar aos novos produtos surgidos além das fronteiras. Essa adaptação exigiu adequações tecnológicas sem precedentes na história da indústria brasileira, com renovações completas de antigos parques industriais. Surge, então, uma nova forma de competitividade. Os produtos tornaram-se commodities, ou seja, seus níveis de diferenciação são mínimos (Ex.: celulares) e as empresas devem buscar novas formas de lucrar com seus produtos. Uma das alternativas de maior destaque que se apresenta para esse fim é redução de custos. Diversos autores da área logística concordam: a logística é o ponto chave de economia de custos para a empresa. Como escreve Ballou (1993)2: "Na firma individual, atividades logísticas absorvem uma porção significativa de seus custos individuais. Estes custos, que são em média cerca de $22 \%$ das vendas (...) determinam muitas vezes se a firma será competitiva. Boa administração é essencial”. (p.38).

Verifica-se, portanto, a necessidade de estudo e aplicação de estratégias e ferramentas para alcançar a redução de custos que apresentem uma maneira eficaz de trazer vantagens sobre a concorrência e conquistar o cliente. A logística abrange um amplo campo de atividades dentro da Cadeia de Suprimentos. Podem ser encontrados diversos segmentos a serem trabalhados separadamente e que, em conjunto, proporcionam os resultados de redução de custo esperados. Um programa de capacitação de fornecedores pode ter resultados tão bons quanto à melhoria de localização dos centros de distribuição. Assim como a melhoria de arranjo físico pode impactar diretamente na lucratividade da empresa. Concordando com Slack (2002)3: "Mudanças relativamente pequenas na localização de uma máquina numa fábrica ou dos produtos em um supermercado ou até mesmo a mudança de salas em um centro esportivo, podem afetar o fluxo de materiais e pessoas por meio da operação. Isso, por sua vez, pode afetar os custos e a eficácia geral da produção".

\section{Fonte de Dados}

Esta pesquisa teve natureza qualitativa em relação aos temas tratados, foram realizadas pesquisas em literaturas científicas e em normas técnicas publicadas nos últimos dez anos. Do ponto de vista dos objetivos, este estudo classifica-se como exploratório e em relação aos seus procedimentos técnicos como bibliográfico; como base de dados, foram utilizadas dissertações, livros técnicos, artigos e periódicos que abordassem o assunto, além de consulta a sites. O tema, em princípio, foi contextualizado frente à competitividade empresarial, foi feita uma revisão bibliográfica sobre o conceito $5 \mathrm{~S}$, suas vantagens, etapas de implantação e exemplos de aplicação, seguido de uma revisão sobre gestão de estoques e a apresentação de estudo de caso envolvendo uma organização do ramo alimentício, levando à finalização com a análise conclusiva do artigo.

\section{O programa 5S}

A ferramenta 5S, também chamada de Housekeeping (conservação da casa), surgiu no Japão nos anos 50, após a $2^{\mathrm{a}}$ Guerra Mundial, com o objetivo de reorganizar o país quando vivia a chamada crise da compatibilidade, no Programa de Recuperação das Empresas Japonesas ${ }^{4}$. Segundo Nadia Vanti (1999) ${ }^{5}$ : “o Programa 5S de Administração nasceu no Japão, quando pais ensinavam a seus filhos os princípios educacionais até a fase adulta." No Brasil, o programa foi lançado no início da década de 1990, conforme Bertaglia (2003) ${ }^{6}$. Consistindo num "sistema de padronização e organização do local de trabalho", o objetivo do $5 \mathrm{~S}$ é criar um local de trabalho visual: autoexplicativo, auto-organizativo e automelhorável, que evidencie aos funcionários uma situação fora do padrão, bem como permita sua correção de forma simples e imediata. Um ambiente limpo, bem organizado, e que fala com você $\hat{e}^{7}$ O Programa tem como objetivo administrar de forma participativa e melhorar o ambiente de trabalho proporcionando qualidade de vida, qualidade de serviço e facilidade na implantação de outros programas de melhoria. Para aplicação do $5 \mathrm{~S}$, é necessária uma modificação do comportamento dos colaboradores, do contrário, não poderá ser concluído. Como afirma Falconi (2004) ${ }^{8}$, "O programa 5S não é somente um evento episódico de limpeza, mas uma nova maneira de conduzir a empresa com ganhos efetivos de produtividade." 
Caso não haja comprometimento dos colaboradores, assim como da alta direção da empresa, o programa não funcionará, como constata a pesquisa SEBRAE feita em 2000, sobre a Gestão da Qualidade Total aplicada às empresas de serviços. Nela, verificou-se que, dos programas $5 \mathrm{~S}$ implantados pelas empresas, $72 \%$ fracassaram devido à falta de comprometimento.

\section{DENOMINAÇÃO DO $5 \mathrm{~S}$}

O programa consiste em 5 Passos relacionados aos "5 Sensos", conforme tabela 1, que apresenta a Denominação dos Conceitos do 5S. Cada senso se aplica sequencialmente para que se possa chegar ao resultado esperado, conforme mostra a Figura 1. A seguir, cada senso e seu significado dentro do programa $5 \mathrm{~S}$ :

Tabela 1. Sensos Programa 5S

\begin{tabular}{|c|c|c|c|}
\hline \multicolumn{2}{|c|}{ Denominação } & \multirow{2}{*}{ Conceito } & \multirow{2}{*}{$\begin{array}{c}\text { Objetivo } \\
\text { Particular }\end{array}$} \\
\hline $\begin{array}{c}\text { Utilização/ } \\
\text { Seleção }\end{array}$ & Seiri & $\begin{array}{c}\text { Separar os } \\
\text { desnecessários }\end{array}$ & $\begin{array}{c}\text { Eliminar do } \\
\text { espaço de } \\
\text { trabalho o que } \\
\text { seja inútil }\end{array}$ \\
\hline Ordem & Seiton & $\begin{array}{c}\text { Situar os } \\
\text { necessários }\end{array}$ & $\begin{array}{c}\text { Organizar } \\
\text { o espaço de } \\
\text { trabalho de forma } \\
\text { eficaz }\end{array}$ \\
\hline Limpeza & Seiso & $\begin{array}{c}\text { Suprimir os } \\
\text { supérfluos }\end{array}$ & $\begin{array}{c}\text { Melhorar o nível } \\
\text { de limpeza }\end{array}$ \\
\hline $\begin{array}{c}\text { Saúde e } \\
\text { Higiene }\end{array}$ & Seiketsu & $\begin{array}{c}\text { Sinalizar as } \\
\text { anomalias }\end{array}$ & $\begin{array}{c}\text { Prevenir o } \\
\text { aparecimento } \\
\text { de doenças, } \\
\text { supérfluos e a } \\
\text { desordem }\end{array}$ \\
\hline Disciplina & Shitsuke & $\begin{array}{c}\text { Seguir } \\
\text { melhorando }\end{array}$ & $\begin{array}{c}\text { Incentivar } \\
\text { esforços de } \\
\text { aprimoramento }\end{array}$ \\
\hline
\end{tabular}

\section{SEIRI: SENSO DE UTILIZAÇÃO}

Basicamente o senso Seiri é saber utilizar sem desperdiçar. Inicia-se pela classificação dos materiais necessários e desnecessários na empresa. Dentro desta, aplicam-se subdivisões como: necessário e de uso frequente; necessário e de uso esporádico; necessário, porém precisa de recuperação; desnecessário, porém útil para outros; desnecessário, porém útil para outros fins e desnecessário e inútil. Após a classificação, realiza-se a correta destinação dos materiais como a guarda, envio para reparo, remessa para outro departamento ou descarte.

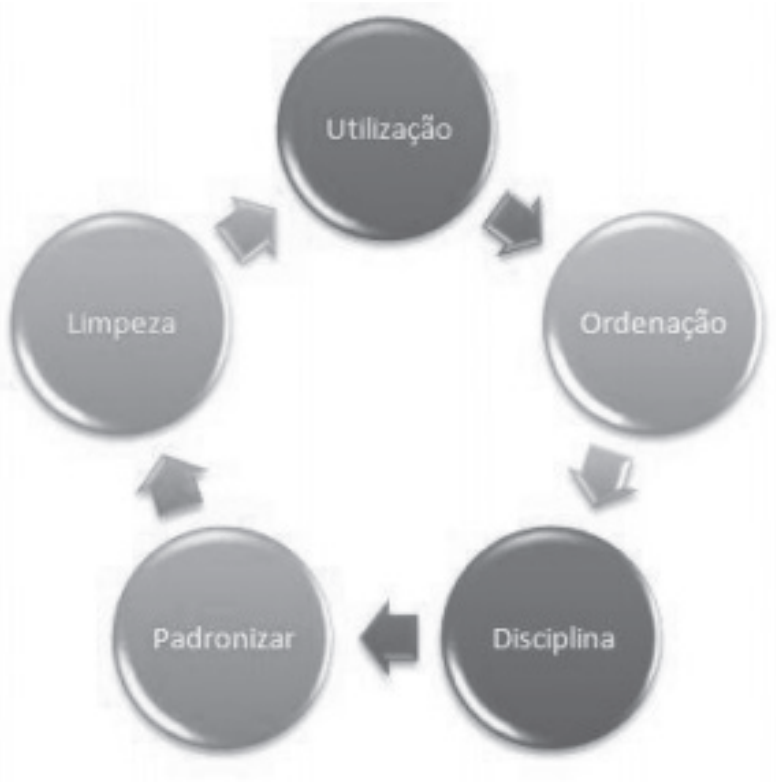

Figura 1. Sequência de aplicação Programa 5S Fonte: http://dijandebarros.wordpress.com

\section{Seiton: Senso de organização}

No senso Seiton, a chave é saber utilizar sem desperdiçar e de forma organizada. Para a gama de materiais classificados como necessários no estágio anterior, deve-se propor a correta estocagem, de forma ordenada, sistematizada e padronizada, de modo a facilitar seu uso, manuseio, localização e guarda.

\section{Seiso: Senso de limpeza}

O terceiro senso consiste em eliminar a sujeira ou objetos estranhos, por meio da identificação de sua origem. Resolver o problema-raíz, resultando na manutenção de um ambiente limpo. Dados e informações também devem ser mantidos sempre atualizados.

\section{Seiketsu: Senso de saúde}

Após a aplicação e consolidação dos três primeiros $\mathrm{S}$, o senso de saúde será cumprido quando tiverem sido criadas condições favoráveis à saúde física e mental, garantindo um ambiente não agressivo e livre de agentes poluentes de qualquer forma, abrangendo até a forma visual. 


\section{Shitsuke: Senso de autodisciplina}

Este senso finaliza o ciclo do $5 \mathrm{~S}$, exigindo para seu cumprimento, a autodisciplina. Aqui os colaboradores entram com uma grande influência e importância. Eles devem seguir as regras e procedimentos criados pelos sensos anteriores, a fim de manter o Programa em funcionamento.

Conforme Oliveira $(1997)^{9}$, aplicando-se os conceitos do $5 \mathrm{~S}$ obtêm-se como resultados positivos: altos níveis de qualidade pessoal e ambiental; manifestação espontânea de criatividade em grupo ao realizar suas tarefas; diminuição dos acidentes; redução do desperdício; conservação de energia física e mental; melhoria do clima organizacional e satisfação coletiva.

\section{Aplicação do Programa 5S}

$\mathrm{O}$ programa $5 \mathrm{~S}$ pode ser aplicado em qualquer empresa, de qualquer ramo e para seu início um projeto de implantação deve ser desenvolvido. É necessária a montagem de grupos de promoção para divulgar o programa, realização de palestras de conscientização e envolvimento dos funcionários, capacitando-os para a realização dos sensos. Preferencialmente, um responsável da diretoria deve participar deste grupo, a fim de demonstrar comprometimento da alta direção aos demais colaboradores. Um grupo de padronização também deverá ser montado para estabelecer regras e procedimentos em cada etapa. Por fim, um grupo de controle é essencial para acompanhar e monitorar os resultados, apontando metas para cada objetivo préestabelecido, pelo grupo de padronização. Um dia de lançamento do programa também se mostra interessante como o Dia D, patrocinado pela empresa, para que todos os envolvidos percebam que uma mudança ocorre e motivem-se a fazer parte desta.

Segundo Alencar $(1998)^{10}$, citado por Nadia Vanti ${ }^{5}$, “a motivação é considerada o componente mais importante no âmbito do indivíduo quanto da organização". Embora sejam recursos e competências de gerenciamento que tornam a inovação possível, a motivação é o elemento catalisador das ações voltadas para a inovação".

\section{Etapas de Implantação do 5S}

A implantação do $5 \mathrm{~S}$ pode ser dividida em 03 etapas:
5S Ativos, 5S Eficazes e 5S Preventivos. A sequência dos procedimentos em cada etapa é seguinte: Separar; Classificar (organizar); Limpar; Padronizar; Manter.

5S Ativos: envolvem a introdução dos conceitos no sentido de "colocar em ordem" o ambiente de trabalho.

5S Eficazes: buscam tornar um hábito a aplicação desses conceitos, mantendo a ordem conseguida por meio do $5 \mathrm{~S}$ ativos e abrangendo um número maior de setores/atividades no local de trabalho, detalhando e aplicando os sensos em cada um deles.

5S Preventivos: buscam aumentar a eficiência na aplicação dos conceitos que já se consolidaram como hábito, por meio da prevenção. A prevenção se consegue pela busca da melhoria continua na aplicação de cada senso mediante indagação permanente sobre quais motivos ainda levam a haver a ineficiência, e intervir nas suas causas.

\section{Casos de Sucesso do 5S}

O Programa 5S foi implantado numa empresa de transformação, demonstrando ser uma maneira fácil, eficiente e de baixo custo para auxiliar na perceptiva da qualidade total em produtos e serviços da empresa $(\text { SILVA, 2003) })^{11}$. Nos estudos realizados por Godoy, Belinaza e Pedrozzi (2001) ${ }^{12}$, o 5S foi implementado trazendo resultados satisfatórios:

Empresa A: mostrou maior credibilidade no comprometimento dos funcionários, acréscimo na organização dos setores, aumento da competitividade e melhora no tratamento com os clientes.

Empresa B: apresentou aumento na organização dos setores e no tratamento dos funcionários com os clientes.

Empresa C: proporcionou melhoria no ambiente de trabalho, operacionalização dos fluxos de trabalho em graus significativos, acréscimo no relacionamento com as pessoas.

Empresa D: ofereceu maior organização dos ambientes de trabalho. Empregando o $5 \mathrm{~S}$ associado a um estilo participativo de gestão em uma Biblioteca Universitária, de acordo com os estudos de Vanti (1999)5, alcançou-se como resultados a melhoria substancial na prestação 
de serviços, criando um clima de confiança, autodisciplina e responsabilidade, além de aumentar a motivação dos funcionários. Numa empresa de armazenagem de médio porte em Minas Gerais, foi implantado o Programa 5S, resultando na Qualidade Total da empresa, apresentando melhoria na organização, maior organização no processo e nos itens utilizados, redução no tempo de busca pelos equipamentos, realização da filosofia de "não sujar" e, em fase de implantação, de programas de saúde e de treinamento aos funcionários (CANTO, SANTOS e GOHR, 2006) ${ }^{13}$.

\section{Facetas da Logística}

Segundo Bowersox, Closs e Cooper (2007)14: "a logística refere-se à responsabilidade de projetar e administrar sistemas para controlar o transporte e a localização geográfica dos estoques de materiais, produtos inacabados e produtos acabados pelo menor custo total". Abrangem-se, em um estudo aprofundado da cadeia de suprimentos: processamento de pedidos, transporte, informações, gestão de estoques, armazenamento e manuseio de materiais. Bertaglia $(2003)^{6}$, por sua vez, destaca como parte integrante da logística o planejamento, compras, produção e a distribuição. Analisando detalhadamente o processamento de pedidos, engloba a previsão de demanda e o nível de troca de informações entre os fornecedores e a empresa, otimizando a comunicação via sistemas EDI e MRP, a fim de obter o melhor resultado em valor economizado.

Entenda-se - EDI (Electronic Data Interchange) ou Intercâmbio Eletrônico de Dados, uma ferramenta que viabiliza a troca de documentos comerciais eletronicamente e, com isso, possibilita diminuir a quantidade de erros gerados pela redigitação e o volume de papel ao mesmo tempo em que aumenta a eficiência e a rapidez na comunicação entre os parceiros comerciais. É a única ferramenta de ecommerce (comércio eletrônico) que está adequada a um contexto automatizado e globalizado.

MRP é a sigla de Material Requirement Planning, que pode ser traduzido por planejamento das necessidades de materiais. O MRP usa uma filosofia de planejamento. A ênfase está na elaboração de um plano de suprimentos de materiais, seja interna ou externamente. O MRP considera a fábrica de forma estática, praticamente imutável. O transporte encontra-se em toda a cadeia, seja na entrada de insumos, como no deslocamento dos mesmos dentro da empresa. Nessa etapa das operações, adiciona-se o estudo da movimentação de materiais. A cadeia logística também engloba a distribuição, ou seja, analisar a melhor alternativa de custo total para se colocar um produto disponível para aquisição do cliente final, levando em conta questões e alternativas de roteirização que, segundo Novaes $(2007)^{15}$, consiste em construir o melhor roteiro para a entrega de um produto e seu modal, considerando fatores de restrições de carga e veículos, distância e localização dos centros produtivos. As informações permeiam toda e qualquer atividade da cadeia de suprimentos, sendo sua velocidade de troca extremamente importante para o funcionamento de uma cadeia enxuta. Exigem-se, para isso, sistemas integrados de informação com participação de fornecedores e clientes, com softwares do tipo ERP (Enterprise Resource Planning ou Sistemas Integrados de Gestão Empresarial (SIGE ou SIG), consiste em uma plataforma de software desenvolvida para integrar os diversos departamentos de uma empresa, possibilitando a automação e armazenamento de todas as informações de negócios), com módulos específicos para as operações da área de Logística.

\section{Gestão de Estoques}

Sabe-se que equalizar a demanda e a oferta de produtos em um mercado é um grande desafio para todas as empresas. Flutuações cambiais, influências no comportamento e métodos de compra, datas comemorativas, crises de abrangência global e outros acontecimentos, afetam diretamente a procura pelos produtos, assim como sua produção e fornecimento. Como já mencionado, a oferta de produtos em um mercado internacional é globalizada, ou seja, os fornecedores se tornaram numerosos, oriundos de vários países, nos diversos continentes e o não atendimento a um pedido pode ocasionar perda direta de clientes ${ }^{7}$.

Faz-se necessária, portanto, a manutenção de estoques que são, conforme Slack (2002) $)^{3}$, “a acumulação armazenada de recursos materiais em um sistema de transformação". Os estoques são uma das facetas da cadeia de suprimentos e também se mostram estratégicos para 
ganhos de economia de escala em compras e transporte, além de proteger a empresa contra oscilações de preço e tempo de ressuprimento. Sabendo-se da necessidade de se manter estoques, surge uma ramificação da Cadeia Logística chamada de Gestão de Estoques, que tem como objetivo, assegurar qualidade no atendimento das necessidades dos clientes internos e externos da organização por meio da administração dos materiais, processos, recursos e informações de toda a cadeia de suprimentos. É importante ressaltar que a gestão de estoques deve ser equilibrada com a demanda e com os sinais do mercado. Interferências do ambiente de negócios devem ser consideradas na definição dos níveis de estoques.

\section{Armazenamento e Movimentação}

Os estoques são essenciais e sua administração adequada é imprescindível para o bom funcionamento da empresa. Para manter estoques, é preciso que as mercadorias estejam sob abrigo e guarda da empresa. Faz-se necessário o uso de depósitos para a recepção da mercadoria, sejam eles próprios ou terceirizados. A armazenagem consiste no espaço físico para as mercadorias estocadas. Os armazéns podem auxiliar na coordenação entre demanda e oferta e proporcionar diversos benefícios à cadeia logística como:

- Localização estratégica = rápido atendimento da demanda.

- Consolidação de mercadorias de mesmo destino = redução no custo de transportes.

- Necessidades de produção = queijos e vinhos que devem ficar armazenados por um período determinado antes de sua comercialização.

A movimentação é um conjunto de operações que envolve a mudança de posição dos recursos do estoque para a produção de bens ou diretamente para sua comercialização. Abrange também a alocação de materiais no armazém quando do recebimento de entregas de fornecedores. Representa uma importante etapa da cadeia logística. Geralmente, os produtos não são produzidos ou demandados no mesmo local em que estão estocados. Faz-se necessário o deslocamento dos bens para o local de processo, embarque ou compra.
Neste aspecto, a movimentação se une ao conceito da logística de distribuição. Por vezes, a movimentação representa a parte principal do atendimento a um pedido urgente ou necessidade inerente da produção. Sua correta administração é necessária para evitar os custos diretos de faltas. Contudo, segundo Ballou (1993) ${ }^{2}$, os custos de armazenagem e movimentação de mercadorias podem absorver até $40 \%$ das despesas logísticas de uma empresa. Por este dado, verifica-se a necessidade da correta administração destes aspectos para o objetivo final de redução de custos mediante melhoria nos aspectos logísticos da empresa.

\section{Custos de Estoques}

Da mesma forma que há ganhos de custo com a adoção de estoques, também existem custos para a manutenção desses e que, caso não sejam bem controlados, podem influenciar até na sobrevivência da empresa. Para Ballou $(1993)^{2}$, há três categorias de custos de administração de estoques, que serão explanadas a seguir:

- Custo de manutenção de estoques: "são os custos necessários para manter certa quantidade de mercadoria por um período de tempo". Podese identificar que qualquer erro na previsão de quantidade ou de tempo necessário para se manter um produto ou matéria-prima em estoque, imobiliza um capital que poderia estar empregado em outras atividades de lucro para a empresa. Impostos, depreciação, seguro e valores de armazenagem por período crescem à medida que a quantidade de produtos estocada aumenta. Controlar a quantidade em estoque e seu tempo de armazenagem é essencial para manter os custos a níveis aceitáveis.

- Custos de compra: Os custos de compra são todas as ações administrativas necessárias para se realizar uma compra, considerando-se o processamento e envio de pedidos, tempo necessário para acompanhamento do processo, recebimento e checagem da mercadoria na entrega e direcionamento para armazenagem. Todo o processo envolve esforço e tempo de funcionários, recursos tecnológicos e materiais, que possuem cada qual seu custo dentro da organização.

- Custos de falta: Os custos de falta podem ser definidos claramente pela fuga de um cliente devido a não entrega de um produto. A empresa 
gastará tanto na tentativa de recuperação do cliente como na prospecção de novos consumidores. $\mathrm{O}$ atraso de entrega, causado por mercadorias em falta também deve ser considerado. O cliente poderá aceitar aguardar pela entrega, contudo terá o direito de reverter o pagamento de seus custos logísticos, como frete e seguro, para a empresa. Verifica-se, portanto que, uma adequada Gestão dos Estoques e seus custos é essencial, impactando diretamente na empresa, que, caso mal administrados, poderá trazer resultados que comprometam sua operação e até mesmo causem sua falência.

\section{Aplicação de Sistemas de Qualidade na Gestão de Estoques}

Segundo Bertaglia (2003) ${ }^{6}$, muitos são os sistemas de qualidade que podem ser aplicados na empresa para a redução de custos e alcance da competitividade, exigida para manter-se no mercado atualmente. Cada empresa adapta-se de forma diferente na utilização dos sistemas de qualidade, de acordo com seu objetivo final e tipo de processo / produto. De acordo com Bertaglia (2003), vários destes sistemas como Kanban, Just-in-Time e 5S, surgiram no Japão e o Ocidente os adaptou e aplicou e continua usando, a fim de chegar à melhor alternativa de custo total, dentro da cadeia de suprimentos. Desde os mais simples sistemas, de fácil implantação, até os mais complicados, essas ferramentas de gestão se apresentam como um recurso eficiente para a gestão dos estoques.

Entre elas, destacam-se:

Programa 5S: Falconi $(2004)^{8}$ afirma que o programa 5S é um sistema de organização do ambiente do trabalho, que envolve todas as pessoas da organização e é visto como uma nova maneira de conduzir a empresa com ganhos efetivos de produtividade. É um estilo participativo de gerenciamento.

Poka-yoke: Para Bertaglia $(2003)^{6}$, o poka-yoke é um conceito "que visa prevenir os erros humanos nos postos de trabalho por meio da identificação de possíveis falhas por meio da inspeção na origem", Considera-se que esta ferramenta previne o erro ocasionado pela atividade repetitiva e otimize o tempo de retrabalho.

Kanban: Segundo Slack et all (2002)3 o Kanban é um sistema para controle e redução dos estoques intermediários na operação de produção, feito através de cartões, operacionalizando o sistema de produção puxada.

Kaizen: Para Peinado (1999) ${ }^{16}$,o Kaizen é um sistema de melhoria contínua que pode contribuir na redução dos estoques e, consequentemente no seu custo.

Just-in-Time: Diversos autores atrelam o sistema JIT à economia de custos dentro da cadeia logística. De acordo com Gonçalves (2007) ${ }^{17}$ : “(...) a metodologia just-in-time busca, como objetivo primordial, a produção de bens e serviços no exato momento em que são necessários, minimizando os custos, retrabalho e otimizando processos (...) procura eliminar perda diminuindo o estoque desnecessário."

TQM: Também definido como o sistema para o Gerenciamento da Qualidade Total no qual todos os processos de trabalho da organização são desenvolvidos de acordo com os princípios de um Sistema da Qualidade. Segundo Falconi (2004) ${ }^{8}$, o TQM é baseado na participação de todos os setores da empresa e de todos os empregados no estudo e condução do controle de qualidade.

TPM: Segundo Bertaglia (2003) $)^{6}$, a TPM (Total Productive Maintenance) consiste em programa para manutenção com máquinas, equipamentos e acessórios de produção e de outras áreas da empresa na busca de um aumento de produtividade para a empresa. Seu objetivo principal é maximizar a eficiência na produção.

SISTEMA ISO 9000: Bertaglia (2003) ${ }^{6}$ afirma que a ISO (Internacional Organization for Standartization) 9000 "é garantia de qualidade total". Sendo aceita mundialmente como a certificação maior da empresa, a ISO é tida hoje, concordando com Bertaglia ${ }^{6}$, como a confirmação de qualidade de que os produtos e serviços prestados pela empresa certificada estão de acordo com suas normas e podem ser aceitos em empresas globais, não importando a localização geográfica ou idioma. Sua variação, a ISO 14000 - ligada ao meio-ambiente - tomou força nas últimas décadas devido à grande preocupação das empresas e seus consumidores quanto à sustentabilidade do processo produtivo. Todas as ferramentas, se bem aplicadas, resultam em ganhos efetivos de produtividade, qualidade e redução de custo, cada qual em seu campo de atuação. 
Contudo, para a implementação de qualquer programa de melhoria na empresa, é necessário que haja uma mudança de cultura. Os executores da mudança precisam integrar os novos aspectos às práticas do dia a dia e é preciso que haja uma preocupação com os aspectos de limpeza, organização e disciplina. Portanto, para início de qualquer modificação nas práticas de gestão, especificamente na gestão de estoques, é necessário implementar os programas que possuem modificações mais simplificadas inicialmente, ou seja, que façam uma mudança de cultura em toda a empresa, porém de forma sutil e que possa ser bem percebida pelos funcionários. Tendo o programa obtido êxito, pode-se partir para a implantação de outros sistemas e programas de qualidade, que exijam mudanças mais profundas de todo o sistema da empresa, como o programa ISO 9000.

Segundo Bertaglia $(2003)^{6}$, o Programa 5S, um exemplo de sistema mais simples, representa não somente uma mudança de local físico de trabalho, mas também uma modificação no ambiente de trabalho que proporciona aos funcionários bem estar, melhor organização das ideias e consequentemente maior produtividade e redução de custos. Portanto, iniciar a implantação das ferramentas de qualidade pelo programa 5S é uma opção iniciar a adoção de Sistemas da Qualidade na empresa.

\section{S na Armazenagem e Movimentação}

Explana-se abaixo a aplicação dos cinco sensos em sua abrangência dentro de um ambiente de armazenagem e movimentação, a fim de economizar custos como resultado de uma gestão eficiente de estoques. Na aplicação do senso de utilização, Seiri, pode-se exemplificar pela segregação de empilhadeiras de uso esporádico, descarte de pallets danificados e sem possibilidade de recuperação destinando-os a um sistema de reciclagem, separação de estantes não utilizadas para alocação de materiais, deixandoas disponíveis a outros departamentos onde haja necessidade identificada.

Itens armazenados ou SKU's (Stock Keeping Unit) (SKU), em português Unidade de Manutenção de Stock está ligado á logística de armazém e designa os diferentes itens do estoque, estando normalmente associado a um código identificador (Dias, 2005) ${ }^{18}$ descontinuados, porém ainda em estoque, devem ser relacionados e informados ao departamento comercial para realização de ações promocionais, a fim de liberar o estoque e o espaço para alocação de produtos de venda atual. O senso de organização, Seiton, pode ser aplicado na organização de corredores, alas e estantes. É possível também colocar materiais de reforço como cintas, lacres, plásticos e máquinas de stretch em áreas próximas à finalização de embalagens e da saída do material, assim como facilitar o acesso às caixas de papelão e fitas de fechamento.

Um quadro para organização das ferramentas de operação das empilhadeiras pode ser confeccionado e alocado próximo ao local no qual os equipamentos estarão segregados. Uma área reservada para as atividades de faturamento e emissão de documentos pode ser providenciada. O terceiro senso (Seiso) relacionado à limpeza, em um ambiente de armazenagem é essencial. Muitas empresas levam seus clientes para conhecer os estoques, portanto a eliminação de focos de poeira assim como a redução de sua origem com telas de proteção em janelas, limpeza constante do chão e ambiente climatizado, devem ser providenciados.

A organização do sistema também deve ser realizada a fim de ordenar os produtos em ordem lógica e atual, resultando na economia de tempo na procura por itens. Para a aplicação do quarto senso, Seiketsu, voltado à saúde, deve-se manter as condições de limpeza e higiene adotadas no Seiso. A comunicação visual clara também de corredores, alas, estantes, códigos de produtos e ordenação FIFO, (First In - First Out ou Primeiro que entra - primeiro que sai) devem ser visualmente atraentes e de fácil entendimento para evitar a poluição visual e possíveis acidentes. Informações simples também evitam a canalização do processo de picking em um único funcionário, proporcionando redução no tempo de processamento de pedido. O quinto senso, de autodisciplina, Shitsuke, procura a manutenção da nova ordem estabelecida. Refere-se ao hábito de manter as regras e o que foi alcançado pelos sensos anteriores. Cabe uma menção de fatores motivacionais, a fim de estimular os colaboradores a manter a ordem e tornar comuns as economias de custos alcançadas. 
Os colaboradores devem participar de todo o processo e sentirem-se envolvidos com esse. Somente dessa forma, poderá ser atingido o quinto senso. Constante estímulo dos resultados, realização de eventos de comemoração do $5 \mathrm{~S}$ e promoção de cursos relacionados ao tema, são algumas atitudes que podem ajudar na motivação dos participantes, dando sempre destaque aos resultados alcançados por eles mesmos.

\section{ESTUDOS DE CASOS}

A empresa estudada já tem quase 30 anos de existência e é especializada na produção de snacks. No início da década de 90, mudou suas instalações para uma nova sede, onde se mantém até hoje, agregando equipamentos modernos ao seu parque fabril. O avanço da tecnologia e a visão do seus fundadores incentivaram a empresa, no início dos anos 2000, a diversificar sua produção, passando a fabricar produtos de outras gramaturas e sabores. Assi, a partir do ano de 2016, iniciou-se a produção por terceirização, pois algumas empresas da região tinham o interesse em produzir snacks a partir de matérias-primas diversas, porém não tinham parque fabril estruturado, assim a empresa estudada começou a oferecer a terceirização de produção. Os últimos três anos foram marcados pela manutenção da produção com redução da mão de obra disponível.

A necessidade da aplicação do $5 \mathrm{~S}$ surgiu após uma consultoria para implementação do Lean Manufacturing ${ }^{7}$ com o intuito de aumentar a produtividade da empresa. Nessa avaliação, foi verificado que, entre vários aspectos, os estoques de materiais produtivos e administrativos, embora armazenados, estavam desorganizados, o que dificultava sua rápida localização e posterior guarda, quando necessário. Com isso, a alta administração decidiu buscar uma solução que envolvesse, além dos estoques e pudesse dar uma nova sinergia à empresa. A ferramenta que melhor se encaixou no objetivo, segundo a administração da empresa, foi o $5 \mathrm{~S}$.

No ano de 2014, quando teve início a discussão sobre o Programa 5S, foram buscados no mercado casos de sucesso na implantação do programa, e quais os profissionais ou empresas capacitadas para tal. Após essa verificação, foram selecionadas pessoas de diversas áreas da companhia para que fossem treinadas e capacitadas para a implantação e na multiplicação dos conhecimentos adquiridos. No decorrer do mesmo ano, foi elaborado o Projeto de Implantação do Programa 5S, contemplando todas as necessidades da ferramenta, adequada à realidade da companhia. Após quase um ano de planejamento e treinamento dos quase 50 funcionários e terceiros, no mês de abril de 2015 foi realizado o Dia da Limpeza, em que todos os funcionários dedicaram 3 horas do seu dia para aplicar os 3 primeiros $5 \mathrm{~S}$ do programa na empresa. No dia seguinte, pode-se verificar a mudança visual da fábrica em relação à limpeza e organização dos espaços. Especialmente, na área de estoques, a mudança foi significativa e visivelmente perceptível. Os itens de estoques, SKUs ficaram mais organizados, identificados, os corredores livres, e "cada coisa no seu lugar", utilizando sinalização por nomes. Os itens inservíveis e de baixo giro se tornaram facilmente identificados, demandando ações para reutilização ou descarte. Os inventários e controles operacionais diários foram facilitados, reduzindo o tempo execução especialmente no processo de picking. A cada mês subsequente, foi realizada uma auditoria de verificação dos três primeiros Ss, e continuou-se também a aplicação dos outros $2 \mathrm{~S}$.

No início de 2016, a empresa possuía o 5S implantado, com $95 \%$ de efetividade, sendo comprovado por auditoria externa, efetuada por funcionários de outras empresas, que também implantaram o programa. O Programa $5 \mathrm{~S}$ além de proporcionar a racionalização dos recursos, reorganização do ambiente de trabalho e estimular a participação colaborativa dos funcionários, permitiu à empresa preparar-se adequadamente para implantação do Sistema da Qualidade baseado nas normas ISO 9000 e 14000, pois a busca por estas certificações faz parte do planejamento estratégico desenvolvidos por esta empresa. A primeira auditoria deve ser realizada ainda em 2016.

\section{Conclusão}

Pode-se concluir que o pressuposto inicial do artigo mostrou-se verdadeiro a partir do estudo de caso apresentado, ou seja, é possível contribuir diretamente para a racionalização de recursos na gestão dos estoques das organizações com a aplicação do programa $5 \mathrm{~S}$, com a reorganização de espaços de estocagem, movimentação de materiais, redução dos itens de estoques SKUs 
descontinuados, redução nos tempos de picking, embalagem e faturamento. Para que o programa alcance sucesso é necessário comprometimento de todas as escalas de hierarquia. A implantação de um programa $5 \mathrm{~S}$ exige o comprometimento da alta direção e depende da participação de todos os funcionários.

O programa aplicado corretamente, também poderá trazer benefícios para as demais áreas da empresa, pois todas certamente terão materiais e espaços para serem reorganizados e os resultados alcançados beneficiarão a todos de forma integrada. A implantação de um programa 5S visa mudar a maneira de pensar das pessoas em direção a um melhor comportamento, tornando-se uma nova maneira de conduzir a empresa para otimização de recursos e consequentemente, ganhos financeiros efetivos.

Dentre os benefícios apresentados para a aplicação do $5 \mathrm{~S}$, destacam-se o aumento do comprometimento dos funcionários, maior organização nos setores, melhoria no ambiente de trabalho criando um clima de confiança, autodisciplina e responsabilidade além do aumento na motivação dos funcionários, melhoria substancial na prestação de serviços e no tratamento aos clientes, maior organização no processo produtivo e nos itens utilizados, redução no tempo de busca pelas ferramentas e equipamentos, implantação de programas de saúde e de treinamento aos funcionários e consequente aumento da competitividade dessa empresa.

Desta forma, este artigo evidenciou a relevância da aplicação conjunta dos conceitos de $5 \mathrm{~S}$ e gestão de estoques, apresentando suas afinidades conceituais como agente facilitador para essa implantação. Por meio dos casos de sucesso apresentados, evidenciou-se também o efetivo potencial de contribuição dessa união para a melhoria da competitividade das indústrias fazendo desta uma alternativa para as empresas combaterem seus problemas organizacionais, buscando a sustentabilidade através do incremento no retorno financeiro, promoção de benefícios sociais e preservação do meio ambiente, fatores esses de importância relevante à busca contínua da excelência empresarial no mundo atual.

\section{Referências}

1. Bizelli, João S.: Barbosa, Ricardo Noções Básicas de Importação. 9. Ed. São Paulo: Aduaneiras, 2002. 266p
2. Ballou, Ronaldo H., Logística Empresarial, 1.ed. São Paulo: Atlas, 1993. $387 \mathrm{p}$.

3. Slack, Nigel et all. Administração da Produção. 2.ed. São Paulo: Atlas, 2002. 747 p. Entrevista com consultor Treinamento 5S. São Paulo (2003);

4. Granda, M. A. et al. Programa $5 \mathrm{~S}$ na fábrica: um programa para implantação do Sistema de Gestão Integrada, 2006, p.55. Monografia (Gestão e Tecnologia da Qualidade), CEFETMG, Belo Horizonte, 2006.

5. Vanti, N. Ambiente de Qualidade em uma Biblioteca Universitária: aplicação do $5 \mathrm{~S}$ e de um estilo participativo de administração. Ci. Inf., vol. 28, n. 3, p. 333-339, 1999.

6. Bertaglia, Paulo R., Logística e Gerenciamento da Cadeia de Abastecimento, 1.ed. São Paulo: Saraiva, 2003, 509 p.

7. Dennis, P. Produção Lean Simplificada - Um guia para entender o sistema de produção mais poderoso do mundo. Porto Alegre: Bookman, 2008.

8. Falconi, Vicente, TQC - Controle Total da Qualidade, 2.ed. Minas Gerais: INDG, 2004. 256 p.

9. Oliveira, J. R. C. Aspectos humanos dos 5 sensos: uma experiência prática. $2^{\mathrm{a}}$ ed. Rio de Janeiro: Qualitymark, 1997.

10. Alencar, J. Como o programa dos oito sensos (8S) pode ajudar na educação e qualificação profissional, reduzindo custos, aumentando a produtividade e combatendo o desemprego. In: XVIII Encontro Nacional de Engenharia de Produção, Niterói, 1998.

11. Silva, Christian E. Implantação de um programa $5 \mathrm{~S}, \mathbf{2 0 0 3}, 8$ p. Artigo Científico - UNIFEI - Campus Minas Gerais.

12. Godoy, L. P.; Belinazo, D. P.; Pedrozzi, F. K. Gestão da Qualidade Total e as contribuições do Programa 5S's. In: Encontro Nacional de Engenharia de Produção, 2001.

13. Canto, L. C. C.; Santos, L. C.; Gohr, C. F. Implantação do sistema $5 \mathrm{~S}$ no setor de armazenagem de uma empresa de pequeno porte do sul de Santa Catarina. In: XXVI Encontro Nacional de Engenharia de Produção, Fortaleza, 2006.

14. Bowersox, Donald J., Closs, David J., CoopeR, M.Bixby, Gestão da Cadeia de Suprimentos e Logística, 2.ed .Rio de Janeiro: Elsevier, 2007. 442 p.

15. Novaes, Antonio G., Logística e Gerenciamento da Cadeia de Distribuição, 3.ed .Rio de Janeiro: Elsevier, 2007. 400 p.

16. Peinado, Jurandir. O papel do sistema de abastecimento KANBAN na redução de inventários,. 1999, 6p. Artigo Científico - UFSC Campus Curitiba

17. Gonçalves, C. et al. Avaliando o grau de implementação dos principais elementos do TPM: um estudo de caso. In: VIII SIMPEP, 2001.

18. Dias, João Carlos Quaresma. Logística global e macrologística. Lisboa: Silabo, 2005 


\section{Paula V. P. Naves}

Instituto SENAI de Tecnologia em Alimentos e Bebidas,- Rua Professor Lázaro Costa nº 348, Vila Canaã, CEP: 74415-420, Goiânia, Goiás, Brasil

E-mail: pvpnaves@gmail.com 